\title{
The relationship between psychopathology, psychosocial adjustment, social support and quality of life in multiple sclerosis
}

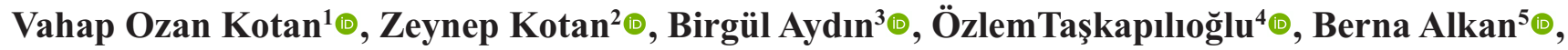 Güven Özkaya $^{6} \odot$, Aslı Sarandöı ${ }^{7} \odot$, Ömer Faruk Turan ${ }^{4} \oplus$, Selçuk Kırlı ${ }^{7}$}

${ }^{1}$ Department of Psychiatry, Başkent University School of Medicine, Ankara, Turkey

${ }^{2}$ Department of Psychiatry, Dr Abdurrahman Yurtaslan Ankara Oncology Training and Research Hospital, Ankara, Turkey

${ }^{3}$ Specialist Psychologist, Dört Mevsim Psychological Counseling Center, Bursa, Turkey

${ }^{4}$ Department of Neurology, Uludağ University School of Medicine, Bursa, Turkey

${ }^{5}$ Department of Neurology, Başkent University School of Medicine, Ankara, Turkey

${ }^{6}$ Department of Biostatistics, Uludă̆ University School of Medicine, Bursa, Turkey

${ }^{7}$ Department of Psychiatry, Uludağ University School of Medicine, Bursa, Turkey

DOI: $10.18621 /$ eurj.382894

\begin{abstract}
Objectives: Multiple Sclerosis (MS) is a chronic disease which affects physical,psychological and social functioning of patients. In this study we aim to indicate psychiatric comorbidity, some psychosocial factors and their associations with quality of life in patients with MS.

Methods: A total of 227 patients underwent psychiatric examination and the following scales were applied: Socio-demographic data form, Hospital Anxiety and Depression Scale (HADS), Multiple Sclerosis Quality of Life-54 (MSQOL-54), Psychosocial Adjustment to Illness Scale-Self report (PAIS-SR) and Multidimensional Scale of Perceived Social Support (MSPSS).

Results: Among 227 patients with MS, 67.8\% $(n=154)$ had psychiatric diagnosis; 24.2\% $(n=55)$ had depression, $19.8 \%(\mathrm{n}=45)$ had adjustment disorder, 14.9\% $(\mathrm{n}=34)$ had anxiety disorder, $7.1 \%(\mathrm{n}=16)$ had dysthymic disorder and $1.8 \%(n=4)$ had bipolar disorder. Patients with a psychiatric diagnosis had lower scores in role limitations due to emotional problems, emotional well-being, health perceptions, social function, cognitive function, health distress and mental health composite of MSQOL-54. PAIS-SR and MSPSS scores were significantly lower in MS patients with a psychiatric diagnosis. PAIS-SR scores were negatively correlated with role limitations-emotional, emotional well-being, social function, sexual function, satisfaction with sexual function, physical health composite and mental health composite scores of MSQOL-54. MSPSS total score was positively correlated with emotional well-being score of MSQOL-54.

Conclusions: In MS patients, there is a high prevalence of psychopathology and it is associated with quality of life, perceived social support and psychosocial adjustment of the patients. Quality of life is reduced especially in emotional and mental aspects in patients with a psychiatric diagnosis. Diagnosis and treatment of psychopathology in MS patients seems crucial to decrease disease burden.
\end{abstract}

Keywords: Multiple sclerosis, psychopathology, psychosocial adjustment, socials upport, quality of life

Received: January 23, 2018; Accepted: March 7, 2018; Published Online: April 13, 2018

Address for correspondence: Vahap Ozan Kotan, MD., Assistant Professor, Başkent University School of Medicine, Department of Psychiatry, Mareşal Fevzi Çakmak Cad., No: 38/9, Bahçelievler, Ankara, Turkey

E-mail:ozankotan79@yahoo.com 
$\mathrm{M}$ ultiple sclerosis (MS) is a chronic inflammatory disease of the central nervous system which causes motor and sensory impairment by progressive demyelinization. It is the most common cause of neurologic disability in young and middleaged adults. MS is twice as common in females as in males [1].

The relationship of psychological and psychiatric disorders with MS is complex. They might be related to psychosocial factors or they might be symptoms resulting from the neuropathological process. They aggravate physical symptoms like fatigue leading to disability, suffering and disruption of family, work and social life adding to the burden of the chronic inflammatory disease [2]. The rate of depression and other psychiatric disorders is greater in MS than in other chronic medicalor neurological diseases [3, 4]. Treating depression actually results in improvements on a number of aspects of social support and there is evidence that depression itself may actually cause reduced social support $[5,6]$. The lifetime prevalence of any anxiety disorder observed in MS was about $35.7 \%$. Female gender, comorbidity of depression, and restricted social support were considered as risk factors, but the diagnosis of anxiety disorders had been overlooked and not been treated in most subjects [7].

The literature about bipolar disorder in patients with MS is scarce. Like depression, mania may occur as part of the physical disorder or secondary to drug treatments. There is a doubled rate of bipolar disorder in MS compared with the general population [8].

Psychosocial adjustment to MS can be understood as the ability to foster a positive outlook on life, continuing to grow and develop in spite of MS [9]. Among the key elements of successful adjustment to a chronic illness are the successful performance of adaptive tasks (eg, adjustment to disability, maintained emotional balance, healthy relationships), the absence of psychological disorders, the presence of low negative affect and high positive affect, adequate functional (eg, work) status, and the satisfaction and wellbeing in various life domains [10].

Social support is defined as the degree to which an individual's needs for socialization, assistance, cognitive guidance, social reinforcement, and emotional sustenance are met through interaction with the social network [11]. Recent research showed that social support acts as primary protective factor for mortality, morbidity and disability in chronic patients by facilitating healthy behaviors and compliance to treatments [12]. In general, the research suggests that social support is related to better psychosocial adaptation to MS [13].

Chronic illnesses have a major impact on all aspects of an individuals' life, affecting physical, psychological and social functioning [14]. Chronic symptoms, long-lasting treatment, incomplete recovery after relapses, the accumulation of new deficits, and the progressive nature of the condition interfere with daily activities of individuals and have negative impact on their wellbeing. Studies show that QoL measurements are constantly lower in patients with MS. Estimation of health related QoL (HRQoL) is necessary when analyzing the effectiveness of treatment modalities and in follow up of patients with chronic diseases such as MS. Main factors related with HRQoL are physical factors (sensitive/motor deficits, fatigue, pain, and sexual/bladder dysfunction), psychological factors (depression, anxiety, cognitive disturbances, and coping strategies) and social factors (family/social relationships and work activity) [15].

In the current study, we aim to investigate the features of psychosocial adjustment to disease, perceived social support, and their relations with health related quality of life in patients with MS. We also aim the relation of these variables with comorbid psychopathology.

\section{METHODS}

This study was conducted at Psychiatry and Neurology Departments of Uludag University Medical Faculty Hospital in Turkey. Two hundred and fifty five patients who applied to Neurology departmentand were diagnosed as MS were recruited. The exclusion criteria for the patients were as follows: psychotic, demented or mentally retarded patients, alcohol or substance abusers, patients whowere on psychiatric treatment during last 3 months, patients who had an active MS episode, patients who were on steroid treatment, patients who had an invasive procedure during last 3 months, patients with another chronic disease other than MS and illiterate patients. After applying the exclusion criteria, 227 patients were included in the study. Physical and neurological 
examinations were done by a neurologist and routine blood tests were applied to all subjects. Patients underwent a psychiatric examination comprised of a semi-structured clinical interview of the DSM-IV-TR [16].The Ethical Committee of the institution approved the study. All subjects gave written informed consent to participate in this study.The assessments were performed using the scales below: Sociodemographic data form, Hospital Anxiety and Depression Scale (HAD), MultipleSclerosisQuality of Life-54 (MSQOL-54), Psychosocial Adjustment of Illness Scale - Self Report (PAIS-SR) and Multidimensional Scale of Perceived Social Support (MSPSS).

\section{Measures}

\section{Socio-demographic data form:}

A form prepared by the researchers in order to obtain socio-demographic data and to assess clinical features related with MS.

\section{Hospital Anxiety and Depression Scale (HADS):}

The Hospital Anxiety and Depression Scale (HADS) is a 14-item scale that provides a brief state measure of anxiety and depression. Turkish version of HADS is valid and reliable in medically ill patients [17].

\section{Quality of Life Scale (QOL) Short Form 36 (SF-36):}

The form was developed by Ware and Sherbourne [18]. Turkish validity study was done by Koçyiğit et al. [19]. It is composed of 36 items that measure eight dimensions: physical functioning, social functioning, limitations of role functioning based on physical problems, limitations of role functioning based on emotional problems, mental health, energy/vitality, body pain and general health perceptions. Higher scores point to increased quality of life [19].

\section{Psychosocial Adjustment to Illness Scale-Self Report (PAIS-SR):}

Developed by Derogatis and Lopez in 1983, this is amultidimensional scale to examine the psychosocial adjustment to the disorder [20,21]. Lower scores from the PAIS-SR scale indicate good psychosocial adjustment to the disorder. PAIS-SR scores below35 are considered as "good psychosocial adjustment", scores from 35 to 51 as "fair psychosocial adjustment" and scores above 51 as "poor psychosocial adjustment". Turkish adjustment of PAIS-SR and its validity and reliability studies in Turkey were performed by Adaylar [20].

\section{Multiple Sclerosis Quality of Life-54 (MSQOL-54):}

Quality-of-Life was measured by the diseasespecific instrument MSQOL-54 (Turkish version). This questionnaire includes one of the most widely used QOL measures, the SF-36, as a generic core and an additional 18 items that are specific to MS. Scoring was performed using the Likert method, and higher values indicated better functioning and well-being. The Turkish adaptation was developed by Tulek in 2006. The MSQOL-54 consists of two sections as physical health composite (MSQOL-54P) and mental health composite (MSQOL-54M). It also has two section scores, 13 category scores and two independent items [22].

\section{Statistical Analysis}

All statistical analyses were performed with SPSS ver. 22.0. Shapiro Wilk test was used as normality test. Continuous variables were compared using Student's t-test for normally distributed data and Mann-Whitney U test when the data were not normally distributed. Categorical variables were compared using Pearson's chi-squared test, Fisher's exact test and FisherFreeman-Halton test. Correlations between variables were tested using Spearman correlation coefficients. A $p$ value $<0.05$ was considered as significant.

\section{RESULTS}

Demographic findings including age, gender, marital status, education level, smoking status and exercise status and data about presence of a psychiatric diagnosis are given in Table 1. Among 227 patients, $32.2 \%(\mathrm{n}=73)$ had no psychiatric diagnosis, $24.2 \%$ $(\mathrm{n}=55)$ had depression, 19.8\% $(\mathrm{n}=45)$ had adjustment disorder, $14.9 \%(\mathrm{n}=34)$ had anxiety disorder, 7.1\% $(\mathrm{n}=16)$ had dysthymic disorder and $1.8 \%(n=4)$ had bipolar disorder.

The clinical characteristics of the patients are given in Table 2 . There were no statistically significant differencebetween patients with or without a 
Table 1. Demographicfeatures of multiple sclerosis (MS) patients

\begin{tabular}{|c|c|}
\hline Demographic features & $\begin{array}{c}\text { MS patients } \\
\quad(n=227)\end{array}$ \\
\hline Age (years) & $37.0 \pm 9.9$ \\
\hline \multicolumn{2}{|l|}{ Gender } \\
\hline Male & $64(28.2 \%)$ \\
\hline Female & $163(71.8 \%)$ \\
\hline \multicolumn{2}{|l|}{ Marital Status } \\
\hline Married & $41(18.1 \%)$ \\
\hline Single & $149(65.6 \%)$ \\
\hline Divorced or widowed & $37(16.3 \%)$ \\
\hline \multicolumn{2}{|l|}{ Education Level } \\
\hline Primaryschool & $113(49.8 \%)$ \\
\hline High school & $73(32.2 \%)$ \\
\hline University & $41(18.1 \%)$ \\
\hline \multicolumn{2}{|l|}{ Smoking Status } \\
\hline Smoking & $49(21.6 \%)$ \\
\hline Nonsmoking & $178(78.4 \%)$ \\
\hline \multicolumn{2}{|l|}{ Exercise Status } \\
\hline Exercising & $68(30 \%)$ \\
\hline Not exercising & $159(70 \%)$ \\
\hline \multicolumn{2}{|l|}{ Psychiatric Diagnosis } \\
\hline Depressivedisorder & $55(24.2 \%)$ \\
\hline Adjustmentdisorder & $45(19.8 \%)$ \\
\hline Anxietydisorder & $34(14.9 \%)$ \\
\hline Dysthymicdisorder & $16(7.1 \%)$ \\
\hline Bipolardisorder & $4(1.8 \%)$ \\
\hline No psychiatric diagnosis & $73(32.2 \%)$ \\
\hline
\end{tabular}

Data are mean \pm standard deviation or number $(\%) . \mathrm{MS}=$ multiple sclerosis

Table 2. Clinical characteristics of multiple sclerosis (MS) patients

\begin{tabular}{lc}
\hline ClinicalCharacteristics & $\begin{array}{c}\text { MS Patients } \\
(\mathbf{n}=\mathbf{2 2 7})\end{array}$ \\
\hline Type of MS & $33(14.5 \%)$ \\
Clinically Isolated Syndrome & $158(69.6 \%)$ \\
Relapsing-remitting MS & $20(8.8 \%)$ \\
Primary progressive MS & $9(4.0 \%)$ \\
Progressive-relapsing MS & $7(3.1 \%)$ \\
Secondary progressive MS & $6.8 \pm 3.5$ \\
Duration of diseas e(years) & $3.5 \pm 1.8$ \\
Number of attacks & $3.1 \pm 1.6$ \\
Number of hospitalizations & \\
Medication & $151(66.5 \%)$ \\
Interferon beta & $36(15.9 \%)$ \\
Glatirameracetate & $29(12.8 \%)$ \\
Natalizumab & $11(4.8 \%)$ \\
Other (Fingolimod, & \\
Mitoxantrone, Cyclophosphamide) & \\
\hline Data are mean \pm standard deviation or number (\%). MS = \\
multiple sclerosis
\end{tabular}

psychiatric diagnosis in terms of demographic variables, MS type, duration of MS, number of attacks and hospitalizations and medication type.

Table 3 shows mean scores of PAIS-SR, HADS, MSPSS and MSQOL-54 in two groups of MS patients with and without a psychiatric diagnosis. Depression $(p<0.001)$ and anxiety $(p<0.001)$ scores of patients with a psychiatric diagnosis are significantly higher than those without a psychiatric diagnosis. PAIS-SR scores of patients without a psychiatric diagnosis were significantly lower than those with a psychiatric diagnosis $(p<0.001)$. Regarding MSPSS; total score, family, friends and significant other score were significantly higher $(p<0.05)$ in patients without a psychiatric diagnosis. Emotional role limitations $(p<$ $0.001)$, emotional well-being $(p<0.001)$, health perceptions $(p<0.05)$, social function $(p<0.001)$, cognitive function $(p<0.05)$, health distress $(p<0.05)$ and mental health composite $(p<0.001)$ domains of MSQOL-54 differed significantly between groups. Patients without a psychiatric diagnosis had higher scores in thesedomains.

Correlation of age, duration of disease, number of attacks and hospitalizations were evaluated with the scores of applied scales. There was a positive correlation between the number of attacks and HADS anxiety score $(\mathrm{r}=.138, p=0.037)$ as the only correlation, and there was not any other significant correlation.

When the scale scores were evaluated, there were significant positive and negative correlations among each other. PAIS-SR scores were positively correlated with HADS depression $(\mathrm{r}=.307, p<0.001)$ and anxiety $(\mathrm{r}=.161, p=0.015)$ scores. PAIS-SR scores were negatively correlated with role limitationsemotional $(\mathrm{r}=-.192, p=0.004)$, emotional well-being $(\mathrm{r}=-.156, p=0.019)$, social function $(\mathrm{r}=-.225, p=$ $0.001)$, sexual function( $\mathrm{r}=-.163, p=0.014)$, satisfaction with sexual function $(\mathrm{r}=-179, p=0.007)$, physical health composite $(\mathrm{r}=-.144, p=0.030)$ and mental health composite $(\mathrm{r}=-.193, p=0.004)$ scores of MSQOL-54.

Multidimensional Scale of Perceived Social Support (MSPSS) total score was negatively correlated with HADS depression $(\mathrm{r}=-.243, p<$ $0.001)$ and anxiety $(\mathrm{r}=-.146, p=0.028)$ scores. MSPSS total score was also positively correlated with emotional well-being $(\mathrm{r}=.134, p=0.044)$ score of 
Table 3. Scale scores and $p$ values of patients with and without pyschiatric diagnosis

\begin{tabular}{|c|c|c|c|}
\hline Scales & $\begin{array}{l}\text { Patients with } \\
\text { psychiatric } \\
\text { diagnosis } \\
(n=154)\end{array}$ & $\begin{array}{l}\text { Patients without } \\
\text { psychiatric } \\
\text { diagnosis } \\
(n=73)\end{array}$ & $p$ value \\
\hline PAIS-SR & $62.2 \pm 15.4$ & $52.7 \pm 16.9$ & $<0.001$ \\
\hline \multicolumn{4}{|l|}{ HADS } \\
\hline Depression score & $9.6 \pm 4.0$ & $4.6 \pm 2.5$ & $<0.001$ \\
\hline Anxiety score & $10.2 \pm 3.4$ & $6.1 \pm 2.6$ & $<0.001$ \\
\hline \multicolumn{4}{|l|}{ MSPSS } \\
\hline Total & $58.7 \pm 15.5$ & $65.1 \pm 13.8$ & 0.002 \\
\hline Family & $20.6 \pm 6.5$ & $22.9 \pm 5.8$ & 0.016 \\
\hline Friend & $18.8 \pm 6.7$ & $20.8 \pm 5.9$ & 0.029 \\
\hline Significant other & $19.9 \pm 7.0$ & $21.4 \pm 5.4$ & 0.022 \\
\hline \multicolumn{4}{|l|}{ MSQOL-54 } \\
\hline Physical function & $55.7 \pm 21.1$ & $59.5 \pm 22.6$ & 0.256 \\
\hline Role limitations-physical & $41.0 \pm 22.1$ & $45.9 \pm 19.9$ & 0.106 \\
\hline Role limitations-emotional & $46.1 \pm 20.9$ & $63.8 \pm 20.1$ & $<0.001$ \\
\hline Bodily pain & $64.3 \pm 18.7$ & $66.5 \pm 24.5$ & 0.376 \\
\hline Emotional well-being & $55.4 \pm 15.6$ & $70.3 \pm 18.4$ & $<0.001$ \\
\hline Energy & $51.3 \pm 19.1$ & $52.8 \pm 18.8$ & 0.639 \\
\hline Health perceptions & $47.6 \pm 18.9$ & $54.5 \pm 17.2$ & 0.006 \\
\hline Social function & $58.6 \pm 18.8$ & $75.4 \pm 20.8$ & $<0.001$ \\
\hline Cognitive function & $70.6 \pm 19.1$ & $76.4 \pm 20.7$ & 0.017 \\
\hline Health distress & $59.8 \pm 17.6$ & $65.8 \pm 20.8$ & 0.026 \\
\hline Sexual function & $61.6 \pm 19.3$ & $65.9 \pm 23.1$ & 0.162 \\
\hline Change in Health & $52.9 \pm 20.5$ & $55.2 \pm 19.9$ & 0.455 \\
\hline Satisfaction with sexual function & $55.6 \pm 18.7$ & $60.9 \pm 22.3$ & 0.124 \\
\hline Overall quality of Life & $54.8 \pm 17.6$ & $59.1 \pm 16.7$ & 0.066 \\
\hline Physical health composite & $52.7 \pm 16.2$ & $56.1 \pm 16.5$ & 0.172 \\
\hline Mental health composite & $50.8 \pm 16.0$ & $65.6 \pm 15.7$ & $<0.001$ \\
\hline
\end{tabular}

HADS $=$ Hospital Anxiety and Depression Scale, MSQOL-54 = Multiple Sclerosis Quality of Life-54, MSPSS = Multidimensional Scale of Perceived Social Support, PAIS-SR = Psychosocial Adjustment to the Illness Scale-Self-Report

MSQOL-54.MSPSS family score was negatively correlated with HADS depression $(\mathrm{r}=-.197, p=$ 0.003 ) score.MSPSS friend score was negatively correlated with HADS depression $(\mathrm{r}=-.176, p=$ $0.008)$ and anxiety $(\mathrm{r}=-.149, p=0.025)$ scores. MSPSS significant other score was negatively correlated with HADS depression $(\mathrm{r}=-.141, p=$ 0.033 ) and positively correlated with health perceptions $(\mathrm{r}=.157, p=0.018)$ and cognitive function $(\mathrm{r}=.141, p=0.034)$ scores of MSQOL-54.

\section{DISCUSSION}

In the present study, we found thatamong 227 patients with MS, $32.2 \%(\mathrm{n}=73)$ had no psychiatric diagnosis, $24.2 \%(\mathrm{n}=55)$ had depression, $19.8 \%(\mathrm{n}=$ 45) had adjustment disorder, $14.9 \%(\mathrm{n}=34)$ had anxiety disorder, 7.1\% $(\mathrm{n}=16)$ had dysthymic disorder and 1.8\% $(\mathrm{n}=4)$ had bipolar disorder. Our study revealed a high prevalence of psychopathology in patients with MS in comparison to what is expected in the general population.A significant prevalence of psychological and psychiatric symptoms in patients with MS, compared to general population and individuals with similar degrees of disability, has been reported in the literature [23]. Among the psychiatric disorders, depression is the most frequently related [24] as our study also reveals. Depression is thought to be more common in MS than in other chronic illnesses and neurologic disorders. Limited data on anxiety disorders in MS patients reveal that anxiety is 
common enough to necessitate consideration in theclinical area [25]. Although, prevalence of bipolar disorder $(1.8 \%)$ is only slightly higher than general population $(1 \%)$ in our study, there are studies suggesting a higher prevalence of about $13 \%$ in MS [26]. General conception is that bipolar disorder and MS coexistence is not common but well proven [27]. To our knowledge there is no study investigating the prevalence of dysthymia in MS.

There are some studies which found associations between depression and severity and duration of disease, age and gender; but those findings could not be replicated in most of the other studies [3, 6, 25, 28]. Clinically, depression and anxiety seem to be associated with disease activity but not with duration or severity. No definite evidence supports the association between interferon beta and depression. Instead, the control of psychiatric symptoms seems to improve the adherence to long-term diseasemodifying drugs [23]. In our study, we found no significant difference between psychiatric situation of patients with demographic and clinical characteristics of MS, in line with literature data.

A diagnosis of MS which usually comes in people's most productive years, has great psychosocial impact [29]. MS adds new demands and challenges to both the individual and the family. People with MS experience loss of roles, relationship changes and financial difficulties. These aspects of the disease have a direct effect on psychosocial wellbeing [30]. The high prevalence $(14.9 \%)$ of adjustment disorders found in our study reflects the psychosocial burden of the disease.In the present study, PAIS-SR scores were significantly higher in MS patients with psychopathology indicating poorer psychosocial adjustment. Poorer psychosocial adjustment is found to be correlated with higher depression and anxiety scores. Literature data supports negative impact of psychopathology on psychosocial adjustment in physical illness [31, 32]. Poorer psychosocial adjustment to chronic illness has also negative impact on quality of life parameters [33]. In a recent study, psychosocial adjustment was found to be a statistically significant predictor of QoL in patients and caregivers in Parkinson's Disease. Psychosocial adjustment process helps patients to fit their social activities and expectations with their new situation and therefore facilitate the reconstruction of their self-identity and their sense of control in the new situation that seems to affect their QoL[34]. Similarly, in the present study, PAIS-SR scores werefound to be negatively correlated with role limitations-emotional, emotional well-being, social function, sexual function, satisfaction with sexual function, physical and mental health composite domain scores of MSQOL-54.

Social support is defined as a type of positive interaction and helpful behavior provided to a person in need of support [35]. A review of the literature revealed that social support was related to positive outcomes on individual's health and well-being and increased individual's adaptive capacity to deal with stress and illness [36]. Social support was found to be an important factor that helped people with MS cope with their diagnosis and symptoms [37]. Numerous studies indicate that social support is an important determinant of HRQoLand depression and anxietyin different chronic diseases [38, 39].Increased social support positively affects outcomes through a number of mechanisms, including decreased levels of depressive affect, increased quality of life, increased access to health care, increased patient compliance with therapies, and direct physiologic effects on the immune system. Low levels of social support could be viewed as a risk factor for depression and anxiety and a target for early intervention by clinicians [40]. In line with this literature data, perceived total, family, friends and significant other social support was significantly lower in patients with psychopathology compared with patients without psychopathology in our study.Furthermore, MSPSS total score was negatively correlated with HADS depression and anxiety scores. Whether lower perceived social support increases the risk of psychopathology or the presence of psychopathology affects the perception of social support is controversial. Having a psychopathology itself could prevent socialization.

Schwartz and Frohner [41] indicated that social support in MS patients had a significant contribution to quality of life. HRQoL correlates strongly with measures of social stigma and perception of social desirability to which close personal relationships are perhaps the biggest influence [42]. In the present study; MSPSS total score was positively correlated with emotional well-being score of MSQOL-54 
indicating relation of social support with emotional well-being. MSPSS significant other score was positively correlated with health perceptions and cognitive function scores of MSQOL-54 indicating the importance of close relationships in mental domains of QoL.

Health-related quality of life (HRQoL) has been more intensively studied in multiple sclerosis (MS) than in any other neurological disorder. Many psychosocial factors such as coping, mood, self efficacy, and perceived support influence the quality of life of patients with MS more than biological variables such as weakness or extent of MRI lesions [43]. Depression is one of the strongest predictors of HRQoL in MS [44]. Depression impairs motivation retarding physical progress, can distort an individual's view of the world and his/her health and reciprocally low quality of life can lead to depression [44]. Anxiety is also a known risk factor for poor HRQoL in many disorders but has rarely been studied in patients with MS. health anxiety involving fears of disease progression is most troubling for many patients with a physical disease [45]. In MS, anxiety has been linked with low HRQoL in some, but not all studies $[46,47]$. Patients with myasthenia gravis and a psychiatric diagnosis were also found to have lower scores in general health, vitality, social functioning, emotional role and mental health domains of SF-36 compared with those patients without a psychiatric diagnosis. Four of these five domains (vitality, social functioning, emotional role and mental health) belong to mental health indicating that having a psychiatric diagnosis is related with decrement mostly in mental aspects of HRQoL [32]. Supporting literature data; mostly emotional and mental aspects of QoL (emotional role limitations, emotional well-being, health perceptions, social function, cognitive function, health distress and mental health composite) were more negatively affected in patients with a psychopathology in the present study. In the presence of psychopathology, the effects of chronic illness and of treatment could be perceived more negatively resulting with more decrement in HRQoL.

\section{Limitations}

There are some limitations of the present study. Cross-sectional design is a major limitation which does not allow to infer causality but only to show associations. Secondly, our study does not have a control group consisting of healthy individuals or patients with another chronic disease. Thirdly, personality disorders which could have a significant impact on psychosocial features were not evaluated in our study.

\section{CONCLUSION}

We have shown a high prevalence of psychopathology in MS patients. Psychopathology has a significant impact on quality of life, perceived social support and psychosocial adjustment. Quality of life is reduced especially in emotional and mental domains if the patient had a psychiatric diagnosis. Social support is an important predictor of at least some domains of QoL and effects psychosocial adjustment. We suppose that our results may have a practical implication. We believe that psychiatric disorders should be carefully evaluated and treated in patients with MS in order to reduce disease burden.Psychiatric consultation should be considered as a key element of approach to MS. Interventions to increase social support should be considered in psychosocial therapeutic protocols. Prospective studies investigating the effects of psychiatric interventions on MS outcomes are needed to verify those findings.

\section{Authorship declaration}

All authors listed meet the authorship criteriaaccording to the latest guidelines of the InternationalCommittee of Medical Journal Editors, and all authorsare in agreement with the manuscript.

\section{Author contributions}

Concept - VOK, ZK, BA, ÖT; Design - VOK, ZK, BA; Supervision - ÖT, ÖFT, SK; Resources and materials - ZK, BA, AS, ÖFT; Data collection and processing - VOK, BA, ÖT, AS; Analysis interpretation and literature search - GÖ, VOK, ZK, ÖT, BA; Writing manuscript - VOK, ZK; Criticalreview - ÖFT, SK.

\section{Conflict of interest}

The authors disclosed no conflict of interest during 


\section{the preparation or publication of this manuscript.}

\section{Financing \\ The authors disclosed that they did not receive any grant during conduction or writing of this study.}

\section{REFERENCES}

[1] EbersGC. Environmental factors and multiple sclerosis. Lancet Neurol 2008;7:268-77.

[2] Ghaffar O, Feinstein A. The neuro-psychiatry of multiple sclerosis: a review of recent developments. Curr Opin Psychiatry 2007;20:27885.

[3] Patten SB, Beck CA, Williams JV, Barbui C, Metz LM. Major depression in multiple sclerosis: a population-based perspective. Neurology 2003;61:1524-7.

[4] Cummings JL, Arciniegas DB, Brooks BR, Herndon RM, Lauterbach EC, Pioro EP, et al. Defining and diagnosing involuntary emotional expression disorder. CNS Spectr 2006;11:1-7.

[5] Gold SM, Irwin MR. Depression and immunity: inflammation and depressive symptoms in multiple sclerosis. Neurol Clin 2006;24:50719.

[6] Mohr DC, Classen C, Barrera M, Jr. The relationship between social support, depression and treatment for depression in people with multiple sclerosis. Psychol Med 2004;34:533-41.

[7] Korostil M, Feinstein A. Anxiety disorders and their clinical correlates in multiple sclerosis patients. Mult Scler 2007;13:67-72.

[8] Sanfilipo MP, Benedict RH, Weinstock-Guttman B, Bakshi R. Gray and white matter brain atrophy and neuropsychological impairment in multiple sclerosis. Neurology 2006;66:685-92.

[9] Marks SF. Nursing assessment of positive adjustment for individuals with multiple sclerosis. Rehabil Nurs 1990;15:147-51.

[10] Stanton AL, Collins CA, Sworowski LA. Adjustment to chronic illness: theory and research. In: Baum A, Revenson TA, Singer JE, eds. Handbook of health psychology. Mahwah, NJ: Erlbaum, 2001.,pp. 387403.

[11] Hirsch BJ. Natural support systems and coping with major life changes. Am J Comm Psychol 1980;8:159-72.

[12] Reblin M, Uchino BN. Social and emotional support and its implication for health. Curr Opin Psychiatry 2008;21:201-5.

[13] Sullivan CL, Wilken JA, Rabin BM, Demorest M, Bever C. Psychosocial adjustment to multiple sclerosis. Int J MS Care 2004;6:98105.

[14] Fekete EM, Antoni MH, Scheiderman N. Psychosocial and behavioral interventions for chronic medical conditions. Curr Opin Psychiatry 2007;20:152-7.

[15] Kes VB, Cengić L, Cesarik M, Tomas AJ, Zavoreo I, Matovina LZ, et al. Quality of life in patients with multiple sclerosis. Acta Clin Croat 2013;52:107-11.

[16] American Psychiatric Association. Diagnostic and Statistical Manual of Mental Disorders: DSM-IV-TR. 4th ed., text rev. Washington DC: American Psychiatric Press, 2000.

[17] Aydemir Ö. Validity and Reliability of Turkish Version of Hospital Anxiety and Depression Scale. Turk J Psychiatry 1997;8:280-7.

[18] Ware JE, Sherbourne CD. The MOS 36-item short-form health survey (SF-36). I. Conceptual framework and item selection. Med Care 1992;30:473-83.

[19] Koçyiğit H, Aydemir Ö, Ölmez N. Reliability and Validity of SF36 in Turkish. Med Treat J 1999;12:102-6.

[20] Adaylar M. Kronik hastalığı olan bireylerin hastalıktaki tutum, adaptasyon, algı ve özbakım yönelimleri. DoktoraTezi, İstanbul: İstanbul Üniversitesi SağlıkBilimleriEnstitüsü, Hemşirelik Anabilim Dalı, 1995. [21] Derogatis LR. The psychosocial adjustment to illness scale (PAIS). J Psychosom Res 1986;30:77-91.

[22] Tulek Z. Determination of Quality of Life in Multiple Sclerosis Patients Who Have Been Followed Regularly. Doctoral Thesis. Istanbul University, Institute of Health Sciences, Department of Nursing, Istanbul, 2006.

[23] Jose Sa M. Psychological aspects of multiple sclerosis. Clin Neurol Neurosur 2008;110:868-77.

[24] Feinstein A. Neuropsychiatric syndromes associated with multiple sclerosis. J Neurol 2007;254:73-6.

[25] Wilken JA, Sullivan C. Recognizing and treating common psychiatric disorders in multiple sclerosis. Neurologist 2007;13:343-54. [26] Schiffer RB, Wineman NM, Weitkamp LR. Association between bipolar affective disorder and multiple sclerosis. Am J Psychiatry 1986;143:94-5.

[27] Sidhom Y, Djebara MB, Hizem Y, Abdelkefi I, Kacem I, Gargouri A, et al. Bipolar disorder and multiple sclerosis: a case series. Behav Neurol 2014;2014:536503.

[28] Galeazzi GM, Ferrari S, Giaroli G, Mackinnon A, Merelli E, Motti $\mathrm{L}$, et al. Psychiatric disorders and depression in multiple sclerosis outpatients: impact of disability and interferon beta therapy. Neurol Sci $2005 ; 26: 255-62$

[29] Compston A, Coles A. Multiple sclerosis. Lancet 2008;372:150217.

[30] Mullins LL, Cote MP, Fuemmeler BF, Jean VM, Beatty WW, Paul RH. Illness intrusiveness, uncertainty and distress in individuals with multiple sclerosis. Rehabil Psychol 2001;46:139-53.

[31] Kocaman N, Kutlu Y, Ozkan M, Ozkan S. Predictors of psychosocial adjustment in people with physical disease. J Clin Nurs 2007;16(3A):6-16.

[32] Kotan VO, Kotan Z, Aydin B, Taskapilioglu O, Yalvac HD, Ozkaya $\mathrm{G}$, et al. Psychopathology, psychosocial factors and quality of life in patients with myasthenia gravis. J Neurol Sci-Turk 2016;33:482-93.

[33] de Ridder D, Geenen R, Kuijer R, van Middendorp H. Psychological adjustment to chronic disease. Lancet 2008;372:246-55. [34] Navarta-Sánchez MV, Senosiain-García JM, Riverol M, Ursúa Sesma ME, de Cerio Ayesa SD, Bravo SA, et al. Factors influencing psychosocial adjustment and quality of life in Parkinson patients and informal caregivers. Qual Life Res 2016;25:1959-68.

[35] Hupcey JE. Clarifying the social support theory research linkage. J Adv Nurs 1998;27:1231-41.

[36] Foote AW, Piazza D, Holcombe J, Paul P, Daffin P. Hope, selfesteem, and social support in persons with multiple sclerosis. J Neurosci Nurs 1990;22:155-9.

[37] Miller CM. The lived experience of relapsing multiple sclerosis: A phenomenological study. J Neurosci Nurs 1997;29:291-304.

[38] Yilmaz Ozpolat AG, Ayaz T, Konag O, Ozkan A. Attachment style and perceived social support as predictors of biopsychosocial adjustment to cancer. Turk J Med Sci 2014;44:24-30.

[39] Staniute M, Brozaitiene J, Burkauskas J, Kazukauskiene N, Mickuviene N, Buneviciuset R. Type D personality, mental distress, social support and health-related quality of life in coronary artery disease patients with heart failure: a longitudinal observational study. Health Qual Life Outcomes 2015;13:1.

[40] Cohen SD, Sharma T, Acquaviva K, Peterson RA, Patel SS, Kimmel PL. Social support and chronic kidney disease: an update. Adv Chronic Kidney Dis 2007;14:335-44.

[41] Schwartz C, Frohner R. Contribution of demographic, medical, and social support variables in predicting the mental health dimension of quality of life among people with multiple sclerosis. Health Soc Work 2005;30:203-12.

[42] Gulick EE. Social support among persons with multiple sclerosis. 
Res Nurs Health 1994;17:195-206.

[43] Mitchell AJ, Benito-León J, González JM, Rivera-Navarro J. Quality of life and its assessment in multiple sclerosis: integrating physical and psychological components of wellbeing. Lancet Neurol 2005;4:556-66.

[44] Lobentanz IS, Asenbaum S, Vass K, Sauter C, Klösch G, Kollegger $\mathrm{H}$, et al. Factors influencing quality of life in multiple sclerosis patients: disability, depressive mood, fatigue and sleep quality. Acta Neurol Scand 2004;110:6-13.

[45] Herschbach P, Keller M, Knight L, Brandl T, Huber B, Henrich G, et al. Psychological problems of cancer patients: a cancer distress screening with a cancer-specific questionnaire. Br J Cancer 2004;91:50411.

[46] Stenager E, Knudsen L, Jensen K. Multiple sclerosis: correlation of anxiety, physical impairment and cognitive dysfunction. Ital J Neurol Sci 1994;15:99-103.

[47] Janssens ACJW, van Doorn PA, de Boer JB, Kalkers NF, van der Meché FGA, Passchier J, et al. Anxiety and depression influence the relation between disability status and quality of life in multiple sclerosis. Mult Scler 2003;9:397-403. 